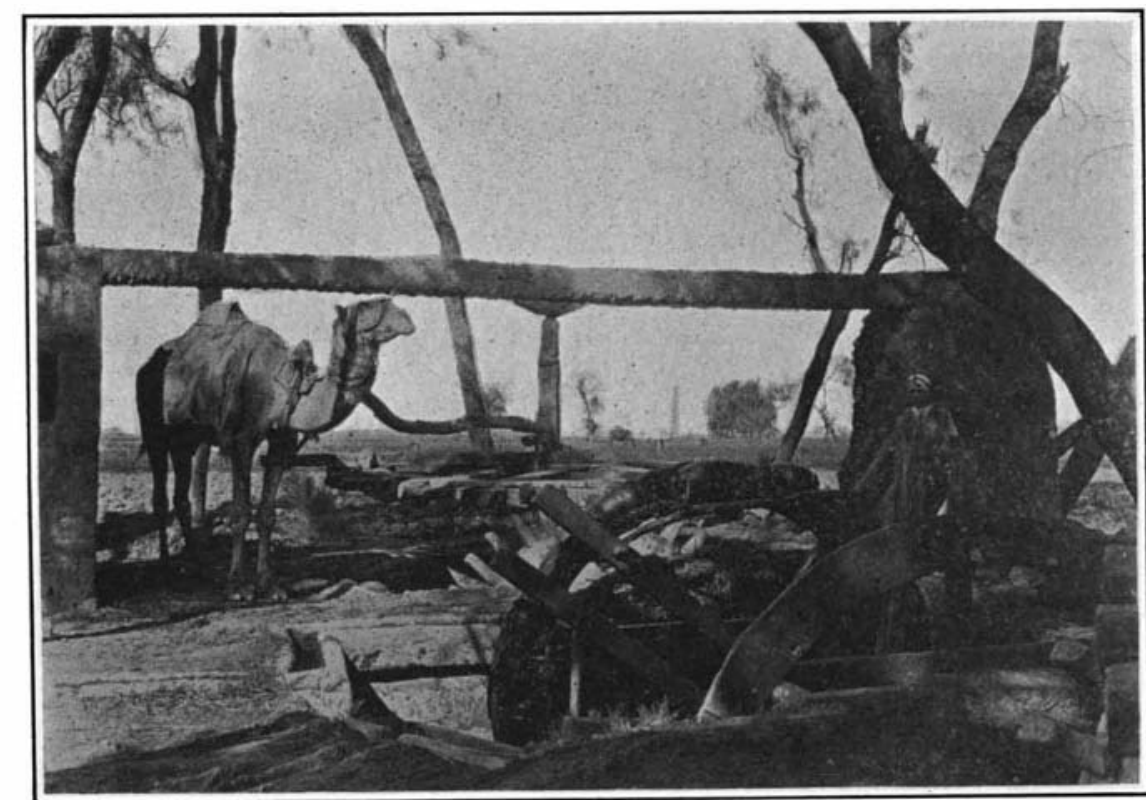

Blindfolded Camel Working a Sakiva. Primitive Method Employed for Local Irrigation Throughout Egypt. When Blindfolded the Animal Has Merely to be Started and Will Then Go Round and Round Indetinitely, Believing That Somebody is Just Behind. From Sunrise to Sunset Throughout the Region the Monotonous Creak of the Sakiya is Heard.

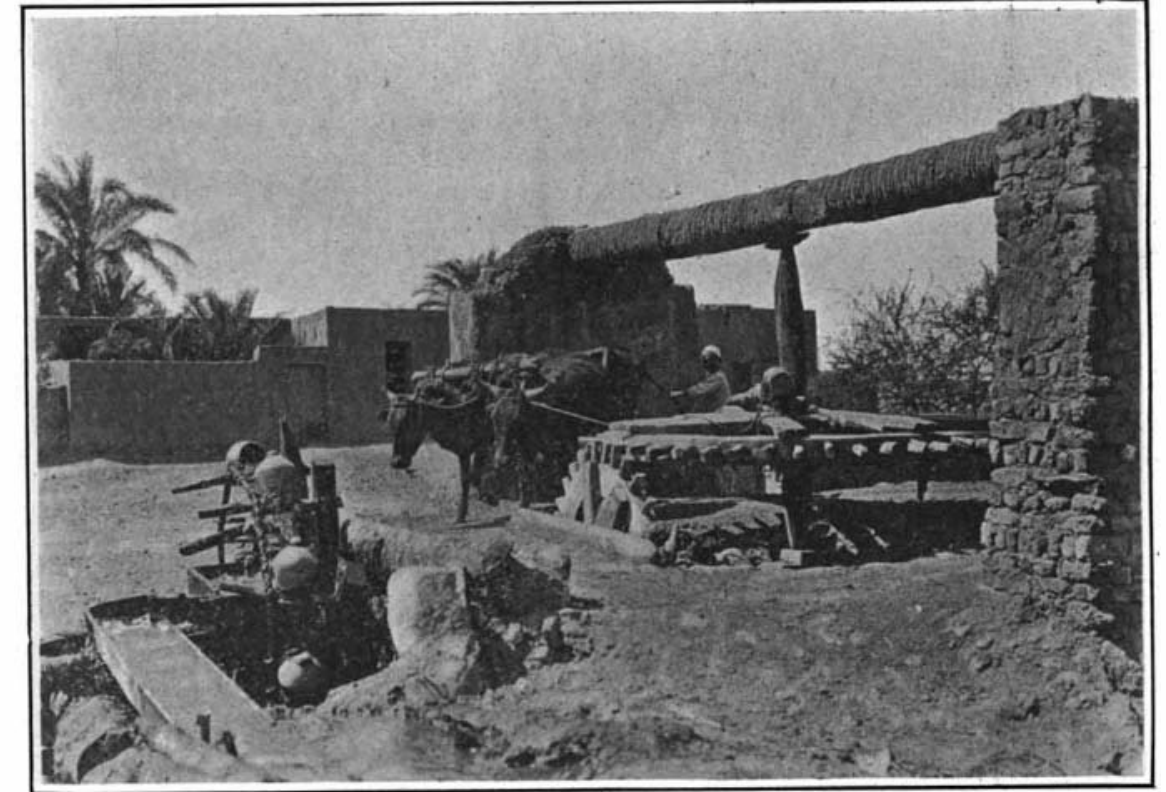

Sakiya Worked by Two Cows. The Earthen Jars Fastened Around the Wheel on the Left Empty Themselves Automatically as They Come to the Surface of the Deeply Sunken Well. The Water From the Trough Flows Out Into the Field Under Irrigation, Connecting With a Series of Canals Cut Into the Ground for the Purpose of Distributing the Water.

\title{
Local Irrigation in Egypt
}

\section{Primitive Methods that Persist to the Present Day}

By A. W. Cutler

Egrpt is a rainless country. It follows, therefore, that artificial irrigation has alweys been necessary for the land. The earliest lings of Egypt realized this. We read that Mena, the first king, who reigned 3400 B. C., was alive to the fact that the annual Nile floods were insufficient to properly nourish more than a comparatively small tract of country, owing to much of the water being lost in the Mediterranean Sea. He endeavored to stop this waste as far as possible, and investigations led to the discovery of a depression, 150 feet below the Mediterranean, in the district known as the Fayoum. This depression was connected with the Nile by a canal, and thereafter when the floods came a quantity of valuable water which would otherwise have been lost was put to good use by a network of ditches intersecting the surrounding country.

This work of King Mena was the first scheme evolved for wholesale irrigation. It was a step in the right direction, but only a step. Egypt has an irrigable area of six and a quarter million acres, and the gigantic task f making this vast expanse of making this vast expanse of lar ductive may be said to have been only just completed by the heightening of the great Assouan dam. This enorinous reservoir, working as it does in conjunction

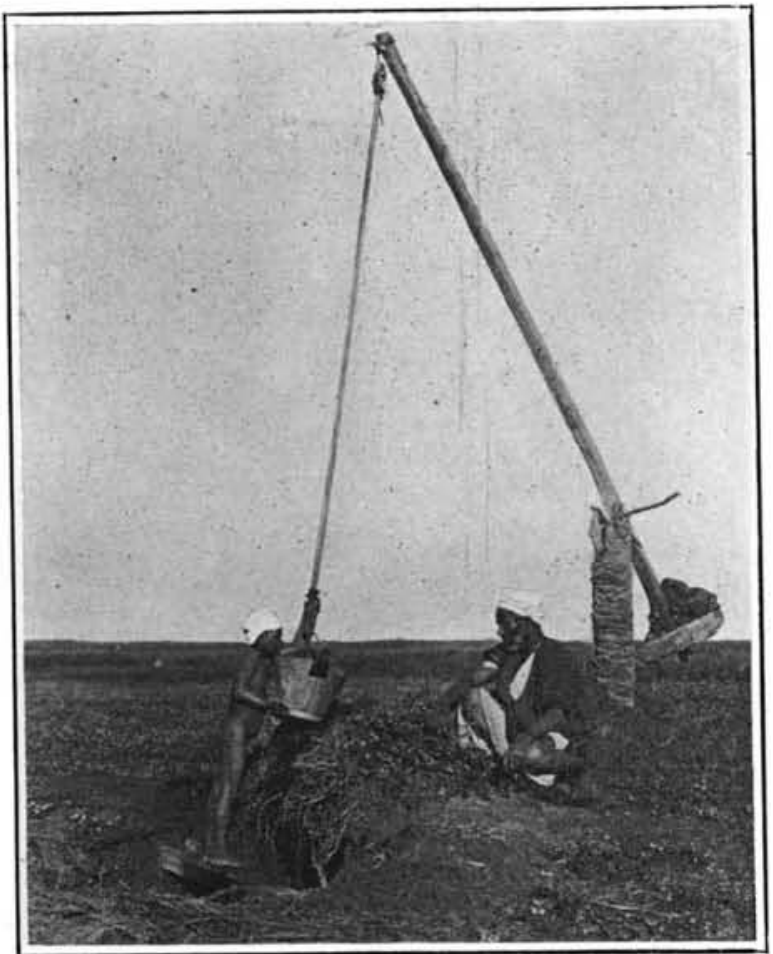

The Shadoof-the Most Primitive Machine in the World for Irrigating the Soil. It Was in Use Before $3400 \mathrm{~B}$. C. The Lump of Mud at the End of the Pole is Sufficiently Heavy to Lift the Bucket Full of Water from the Well Below. Two or More Shadoofs May be Worked in Series. with the barrages at Esneh, Assiout and Cairo (the Delta barrage), satisfactorily discounts the absence of rain, and a plentiful supply of water is now assured for the whole of Egypt.

In spite, however, of these marvellous engineerin feats, local irrigation has still to be practiced. It constitutes the most important item in the daily life of the fellah-the Egyptian peasant. The four barrage over the Nile merely guarantee an abundant 'supply of water in the numerous canals intersecting the entire country. This water during the greater part of the year has to be distributed over the fields by local labor. The methods employed are threefold. It is done by the sakiya, the taaboot, and the shadoof.

As the train rushes along between Alexandria and Cairo, ever and anon will be heard a distant creak, creak, creak, borne in through the open windows on the deliciously warm, scent-laden air, lulling to sleep or exciting the attention of the listener, according to his temperament. It is the sakiya at work out in the fields. Usually close to one of the aanals, you see these primitive inventions constantly all the way up to Cairo. And you will note them by the banks of the Nile from Cairo to Assouan, a distance of 600 miles.

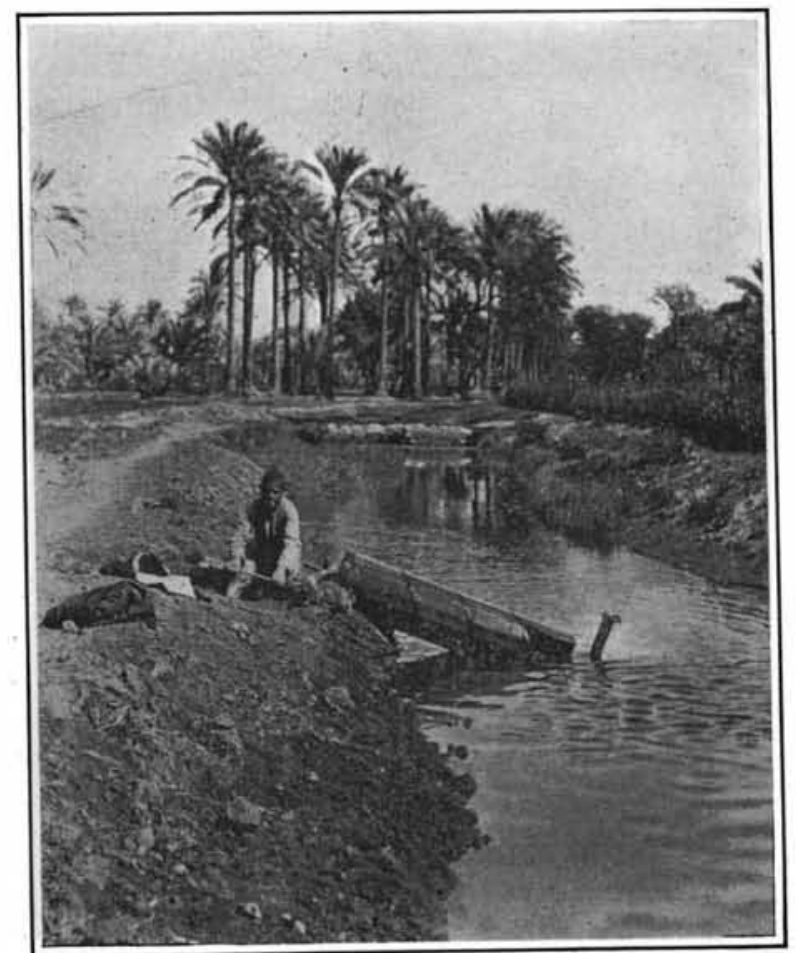

The Taaboot, or Archimedean Wheel, Another of the Laborious Devices Employed in Erypt for Local Irrigation. It is Simply a Long Wooden Tube Fitted Inside With a Spiral Arrangement Made of Thin Laths. As the Device Revolves the Water is Fairly Screwed Up from the Canal.
Near Luxor and farther south, where the heat is great even in winter, you will see half naked and sometimes wholly naked boys engaged in the monotonous, unending task of driving the animals bound to these sakiyas. Round and round they.go; creak, creak, creak goes the sakiya. You hear it from sunrise to sunset. There is no surer cure for a wornout nervous system than the glorious air of the Nile, and the creak of the old sakiyas.

The construction of the sakiya is very simple. The ends of the trunk of a palm tree rest on two vertical supports of sunbaked bricks. Underneath the trunk in the center is the point of a stout wooden pin, which pierces a cogged wheel, arranged horizontally. The cogs of this wheel fit into the eogs of a similar wheel, placed vertically. A shaft from the latter wheel connects with a third wheel, around which have been fastened a number of inverted earthen jars.

A water buffalo, a cow or a camel is the motive power of this clumsy mechanism. Harnessed to the horizontal wheel they walk round in a circle, and as the wheels revolve the jars descend and ascend a deeply sunken well, emptying themselves automatically into a wooden trough as they come to the surface. The water flows

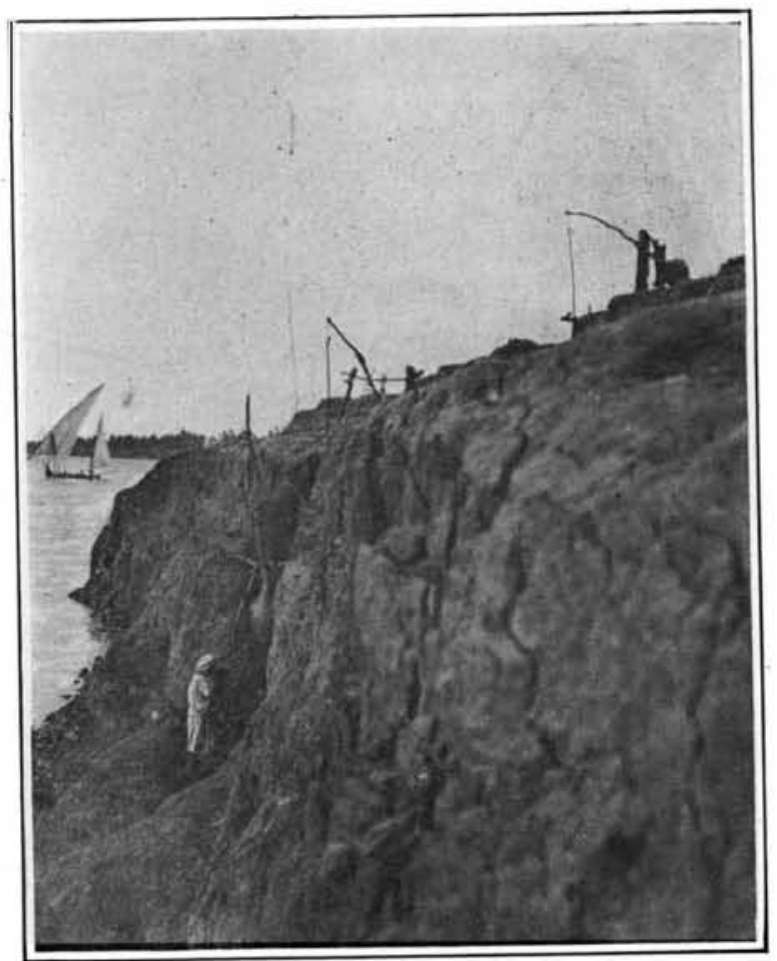

Three Shadoofs on the Banks of the Nile Operating in Series. The Man at the Top Empties his Bucket Into a Canal, Which in Turn Feeds Other Similar Canals, Intersecting the Surrounding Land. Thus the Land is Literally Irrigated by a Bucketful of Water at a Time. 


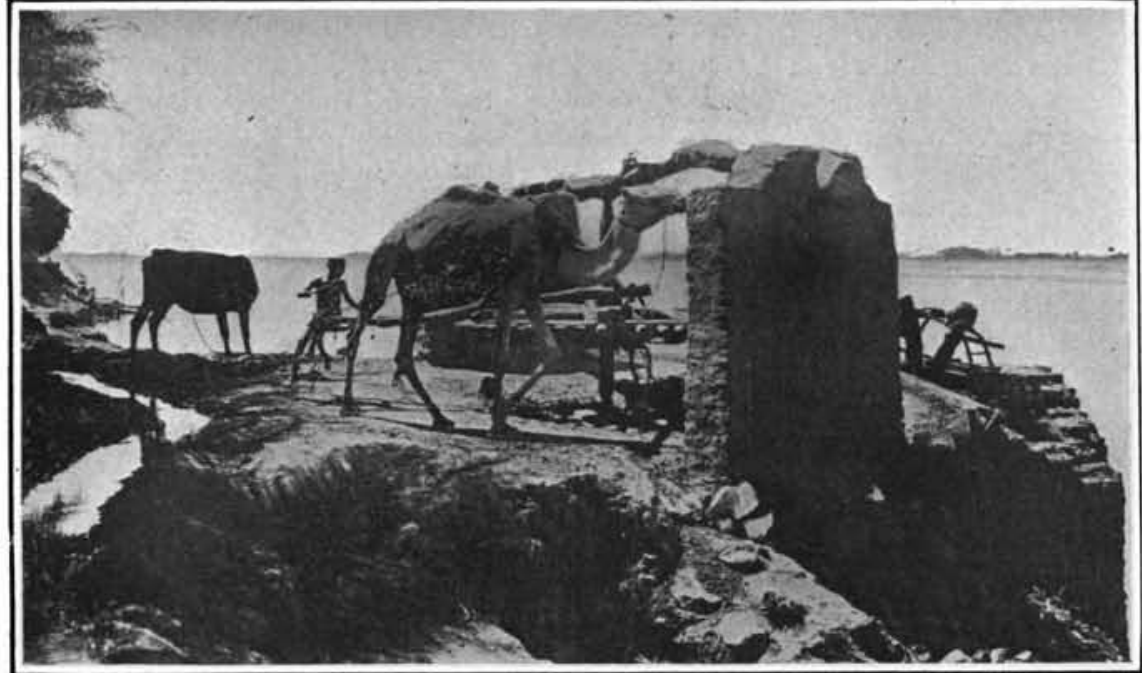

Sakiya on the Banks of the Nile. A Cog-wheeled Arrangement Revolves a Wheel, Around Which Are Fastened Earthen Jars. These Descend and Ascend a Well, Emptying Into a Trough as They Come to the Surface.

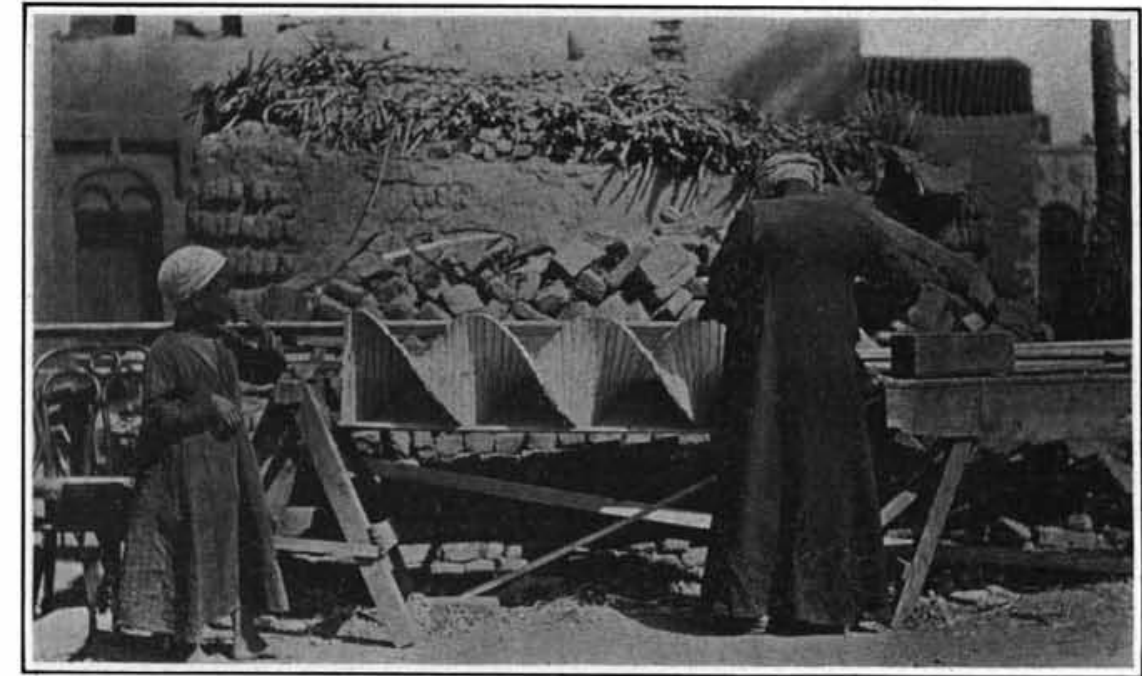

Making a Taaboot. It Will be Seen From This Picture That the Water Needed for Irrigation is Literally Screwed From the Canal. This is the Wellknown Principle of the Archimedean Screw. out into the field under irrigation, being distributed by a series of grooves, or tiny channels, intersecting the piece of ground.

Very often the animals working these sakiyas are blindfolded. This has the effect of keeping them "on the job," without being driven. Once started, they will go round and round indefinitely; believing, no doubt, that their master is just behind, while, as a matter of fact, he is at work in the fields.

The sakiya of Lower Egypt, always referred to as the water wheel of the Delta, is a somewhat more modern scheme and distributes the water faster than the antiquated sakiya of Upper Egypt. The wheel, which descends the well, is similar in construction to a huge elumsy cart wheel, minus spokes, and hollow from rim to hub. Into one side of this wheel holes are cut a few inches apart, and as it revolves the water enters through these openings, and is discharged after the manner of the old type sakiya, only in greater volume.

Laborious and slow as this system of irrigation is, it is rapid in comparison with the taaboot, or Archimedean wheel. This is simply a long wooden tube, fitted inside with a spiral arrangement, made of thin laths. One end of the tube is fixed in a canal, and the wheel is operated by an iron handle attached to the other end, which is seized by a man sitting on the ground, the tube being turned round and round. A it revolves the water is literally screwed up from the canal. It is conveyed to the field under irrigation in the manner already described.

But by far the most strenuous method adopted by the Egyptians for local irrigation is the shadoof. feel that I can afford to be dogmatic here, and state positively that the shadoof is the most ancient contrivance in the world still in use. Crude carvings of this most primitive device of primitive man may be een on the walls of the prehistoric temples around Luxor. It may have been an old invention even in the days of King Mena. Its origin has never been traced.

A child could make a shadoof. A section of a tree trunk, a wooden pin, two long poles, a lump of mud a piece of cord and a bucket-these are all the materials needed. The tree trunk is fixed in the ground vertically. One of the poles is now adjusted see-saw fashion ove the top of the upright trunk, and held in position by means of the wooden pin. At the base of this pole the lump of mud is placed. At the top of the pole the piece of cord is attached, and from it the other pole suspended. At the bottom of this pole the bucket is fastened. There you have your shadoof all ready for work.

The man or boy working the shadoof merely draws down the bucket and sinks it into a deep well dug directly beneath. The lump of mud at the end of the other pole is sufficiently heavy to lift the bucket when full. All that now remains to be done is to empty the bucket into the groove cut for the reception of the water, which is distributed by means of the network of tiny channels. As in the case of the sakiya and taaboot the shadoof As in the cas of the sakide and the is usually seen b four and even five shadoofs may be observed working together in conjunction with one another. The man on the river level empties his bucket into a depression in the bank about even with his head. This water is bucketed up in a similar way by the man above him. The man on the top of the bank now lowers his bucket (assuming there are only three shadoofs in operation) and deposits the water therefrom into the aforementioned groove.

Thus, every single bucketful of water is handled three times before it finally reaches the section of land being irrigated!

\section{Some Physiological Considerations in Lighting Problems*}

\section{The Ideal System would be a Combination of Direct and Indirect Lighting}

By W. F. Schaller

THE importance of physiological considerations in the design of systems of illumination has not generally been realized by engineers. This phase of the problem particularly merits attention in the lighting of libraries, schools, offices, and textile mills, where, very often, the schools, offices, and textity and quantity of work done depend directly on quality and quantity of work done depend directly on eye comfort-or discomfort. The problem, in any case, is efficiency. Efficiency of illumination may be define simply and specifically by the purpose of illumination, i. e., the end sought is a physiological process--sight The eye is a physiological camera. The light flux entering the eye is varied in its physical quantity by the reaction of the eye on the light flux density, in contracting or expanding the pupil, i. e., in changing the size of the aperture. The retina, on the rear in terior of the eyeball, is comprised of two classes of nerve terminals, designated as rods and cones, whic are sensitive to the light flux which has entered and arve as the origin of the sense of sight. Behind the iris the muscular sheet which carries and controls the pupil, is a converging lens hung in a circular muscle by whose contraction or distention focus is varied to accommodate for the distance of the objects viewed.

Three theories, those of Hering, Ladd-Franklin and König, are now most generally accepted to account for the phenomenon of sight. As given, the first two are color theories and the third one explains Seh-schärfe, the ability of distinction. Prof. Ewald Hering main tains that the retina contains three chemical substances, each of which is capable of two opposed processes, decomposition and recomposition. With the assumption of four primary colors, red, green, blue and yellow, with white and black, one pair such as red and green may act on a substance, red destroying and green building it up. The otber two pairs act similarly on the other two substances. A theory advanced by $\mathrm{Mr}$. Ladd-Franklin of Johns Hopkins University states that

* Reproduced from the General Electric Reriew.

the retinal rods are sensitive to white light only and the cones to the colors. Accepting the theory that there are three primary colors, red, yellow and blue, she

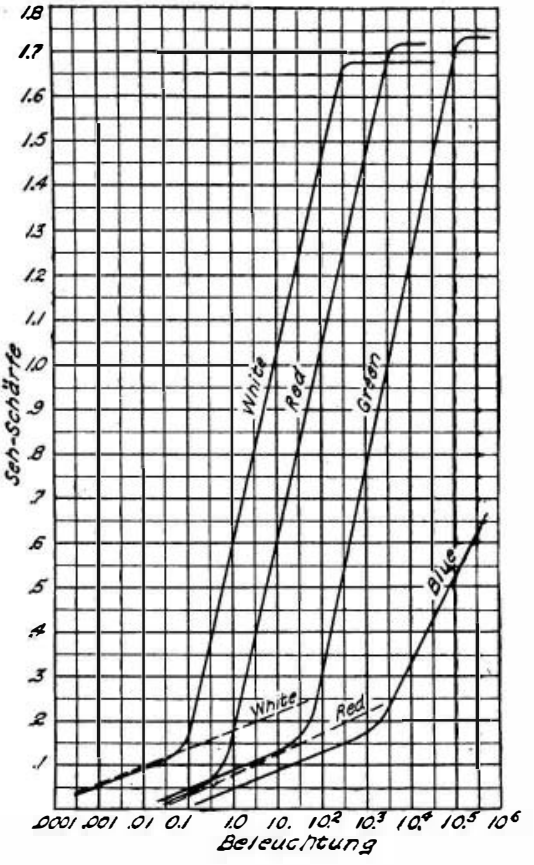

Fig. 1.

says that the cones are composed of three kinds of molecules, each one being sensitive to light of one of the

${ }^{1}$ Red, yellow and blue were the three primary colors used by artists, and are sometimes given now as pigment primaries. The light primaries, however, are red, green and violet. The old primaries (red, yellow and blue) were obtained by a negative method, and are really the complemen-
taries of the actual positive light primaries. three colors. When light of any one of these colors enters the eye it breaks away or decomposes a numbe of the molecules sensitive to it, in proportion to its intensity. The violence of the action then is transmitted to the brain as distinctness of vision.

The following explanation of the phenomenon of sight wap presented by Dr. Arthur König of the University of Berlin before the Royal Academy of Sciences at Berlin in May, 1897. This scientist made an elaborate set of tests to determine the relation between the ability of perception and the intensity of the illumination. Briefly, his method consisted in using the eye to distinguish characters, similar to those used by the oculist, under varying illumination intensities of the colors white, red, green and blue. The ability to see was measured in some arbitrary units and plotted as Sehschärfe against Beleuchtung or illumination, with results as shown in Fig. 1. The following general equation is found to fit the curves:

$S=a(\log B-\log C)$

where

$S$ is ability to distinguish, Seh-schärfe.

$B$ is intensity of illumination.

$a$ is a constant depending on the nature of the light and is about ten times as great after the bend in the curve as before.

$C$ is a constant inversely proportional to the Helligkeitswerth, or "brightness" of the light. Based on these results the logarithmic law of sensation as applicable to the eye was discovered and the following theory evolved: That the rods of the retina are affected by the lower values of light entering the eye and the cones by the higher values. Thus the factor $a$ is smaller when the rods are affected, and larger when the cone come into play. The bend in the curve marks the transition point; which is not sharp, however, since the transfer is more or less gradual and the rods and cones may be active simultaneously. Further, $\boldsymbol{C}$ has 